\title{
Evaluation of the feasibility and effectiveness of a health facility-based combined with home-based early childhood development intervention in Siaya County, Kenya: a cluster-randomized control trial
}

\author{
Patricia Kitsao-Wekulo ${ }^{1 *}$, Hermann P. P. Donfouet ${ }^{2}$, Silas Onyango ${ }^{1}$, Milka Wanjohi ${ }^{1}$, \\ Debjeet Sen $^{3}$, Matthew Frey ${ }^{3}$, Loida Erhard ${ }^{3}$, Ranju Baral ${ }^{3}$, Christopher Obong' ${ }^{4}$, \\ Oscar Kadenge $^{4}$, Beatrice Oyugi ${ }^{4}$, Rachel Kavithe ${ }^{4}$, Dickens Omedo ${ }^{4}$, Amina Abubakar ${ }^{5}$, \\ Teresa Mwoma $^{6}$, Stewart Kabaka ${ }^{7}$, Mark Tomlinson ${ }^{8}$, Linda Richter ${ }^{9}$, Cyril Engmann ${ }^{10}$, \\ Elizabeth Kimani-Murage ${ }^{1}$
}

\author{
${ }^{1}$ Maternal and Child Wellbeing Unit, African Population and Health Research Center, Nairobi, Kenya \\ ${ }^{2}$ Data Measurement and Evaluation Unit, African Population and Health Research Center, Nairobi, Kenya \\ ${ }^{3}$ PATH-US Office, Seattle, WA, USA \\ ${ }^{4}$ PATH- Kenya Office, Nairobi, Kenya \\ ${ }^{5}$ Neuroassessment Unit, KEMRI-Wellcome Trust Research Programme, Kilifi, Kenya \\ ${ }^{6}$ Department of Early Childhood Studies, Kenyatta University, Nairobi, Kenya \\ ${ }^{7}$ Newborn, Child and Adolescent Health Unit, Ministry of Health, Nairobi, Kenya \\ ${ }^{8}$ Department of Global Health, Stellenbosch University, Matieland, South Africa \\ ${ }^{9}$ DST-NRF Centre of Excellence in Human Development, The University of the Witwatersrand, South Africa \\ ${ }^{10}$ Department of Pediatrics and Department of Global Health, University of Washington, Seattle, WA, USA
}

Received: 22 April 2020

Revised: 07 June 2020

Accepted: 15 June 2020

\author{
*Correspondence: \\ Dr. Patricia Kitsao-Wekulo, \\ E-mail:kadwek05@yahoo.com
}

Copyright: ( ) the author(s), publisher and licensee Medip Academy. This is an open-access article distributed under the terms of the Creative Commons Attribution Non-Commercial License, which permits unrestricted non-commercial use, distribution, and reproduction in any medium, provided the original work is properly cited.

\section{ABSTRACT}

Background: Approximately 250 million (43\%) children under five years in low- and middle-income countries are at risk of sub-optimal development. Of these, $67 \%$ are found in sub-Saharan Africa due to exposure to multiple risks, including inadequate stimulation at home. In order to promote early childhood development (ECD), an intervention integrating ECD content into routine facility-based health services and supporting ECD policy and advocacy is currently being implemented in Siaya County. In addition, parental counseling on early stimulation is integrated into home-based visits by community health volunteers. We aim to evaluate the intervention's operational feasibility, effectiveness and cost-effectiveness.

Methods: The study is a cluster-randomized controlled trial using a mixed-methods approach. The study is being conducted in Bondo sub-county in Siaya County. The study has three arms. Arm 1 will receive a health facility-based ECD intervention. Arm 2 will receive the health facility-based ECD intervention combined with home-based ECD counselling. Arm 3 (control) will receive standard care. Six health facilities in each study arm (18 in total) will be randomly selected from wards within the sub-county. We aim to recruit and follow-up 699 mother/caregiver-child dyads, 233 in each arm. Pregnant women are recruited when they visit health facilities during the third trimester. Analysis will involve estimating the effect of the intervention using mixed linear models and the Difference-inDifferences estimator.

Conclusions: The data generated from this study will provide much-needed information for program design and implementation of interventions aimed at promoting ECD in Kenya and other sub-Saharan African countries.

Trial Registration: Current Control Trial is ISRCTN11561283.

Keywords: Early childhood development, Inadequate stimulation, Operational feasibility, Kenya, Health facilitybased ECD intervention, Home-based ECD counseling 


\section{INTRODUCTION}

Child survival has improved globally, with under-five mortality reduced by 53\% between 1990 and 2015, owing to improved socioeconomic conditions, health systems and access to health services. ${ }^{1}$ However, even though more children are surviving, approximately 250 million children younger than five years in low- and middleincome countries (LMICs) are at risk of not achieving their developmental potential. ${ }^{2}$ The risks include malnutrition, chronic poverty, and inadequate cognitive and social-emotional stimulation. Recent studies indicate a $71 \%$ increase in disability rates for children in subSaharan Africa (SSA) attributed to the increased survival of vulnerable children who may not necessarily receive the required support. ${ }^{3}$ Other potential risk factors include poor maternal education, harsh parenting, maternal depression, environmental pollution, and infectious diseases. ${ }^{4}$ Children who survive should be given the best chance to reach their full potential. ${ }^{1}$ The period from conception to a child's second or third birthday when the brain develops - and grows physically in size - most rapidly, represents the most critical time in a child's development as it lays the foundation for later wellbeing. ${ }^{5}$ The plasticity of children's brains during this period and their high degree of adaptability render them capable of benefitting the greatest from early childhood development (ECD) interventions. ${ }^{6}$

Interventions aimed at enhancing caregiver-child relationships are considered strategic in improving a child's survival, health and development. ${ }^{5}$ UNICEF's extended care model outlines proper feeding and psychosocial stimulation as being integral to children's growth and development. ${ }^{7}$ Such behaviors may be promoted through parenting interventions that enhance responsive and emotionally-supportive parent-child interactions, improve responsiveness in feeding and care for young children, increase attachment, improve communication, encourage learning, and promote speech and language, positive discipline and problem-solving. ${ }^{8}$ These parenting interventions may be delivered through home visits, community groups, or integrated within the health system. The World Health Organization (WHO)/UNICEF's Nurturing Care Framework illustrates how existing programs can be enhanced to comprehensively address young children's needs, and reiterates the need for holistic interventions that enable children to reach their full potential. ${ }^{9}$

Integrating ECD interventions into routine health services has several advantages including: enhancing good coverage and compliance with child health visits; averting additional staff costs through implementation by existing staff; no additional time required for parents at the clinic; and, no adverse effects on the nutrition or immunization status of children. ${ }^{10}$ In many LMICs, the health system may be used to facilitate the delivery of ECD interventions as it is often the only existing infrastructure that consistently and regularly reaches young children. ${ }^{11}$ To illustrate, in a sequentiallyconducted controlled trial to determine the efficacy and safety of the Care for Development Intervention (a predecessor to Care for Child Development (CCD)), delivery of the Care for Development messages during acute healthcare visits by trained physicians resulted in more optimal stimulation of young children by caregivers in the intervention compared to the comparison group. ${ }^{12}$ Another study exploring integration of responsive stimulation into home visits delivered by community health workers (CHWs) showed significant benefits on early child outcomes. ${ }^{13}$ Further, a systematic review evaluating the effects of integrating child stimulation and nutrition interventions on child development and nutrition status showed similar findings. ${ }^{14}$ The results of Chang and colleagues who developed a parent training package based on video modeling integrated into routine primary healthcare visits in the Caribbean demonstrated improvements in child cognitive development and mothers' knowledge of child development. ${ }^{10}$ The feasibility of integrating child stimulation into primary care was tested among undernourished children and found to be beneficial for both child and caregiver outcomes. $^{15}$

In low-income settings and particularly in SSA, there are few studies on the effectiveness of integrating ECD content and screening for developmental milestones into the health system. Moreover, the literature on the effectiveness of ECD interventions in changing caregivers' knowledge, attitudes and practices (KAP) is sparse. For instance, even though not specific to developmental outcomes, a study in South Africa demonstrated that, apart from improving the growth of the index child, a home-based maternal and child health intervention delivered by community health volunteers (CHVs) had a significant effect on the growth of other children within the same household aged under six years. ${ }^{16}$ Provision of a basic home stimulation programme during clinic visits has also been shown to significantly improve developmental outcomes in young children infected with HIV. ${ }^{17}$ With regards to costeffectiveness, most studies have assessed the cost-benefit of preschool-based ECD interventions on school readiness, school achievement and performance among older children. With the aid of a cluster-randomized control trial on children aged 0 to 24 months, a study in rural Pakistan compared the effectiveness and costs of integrating three ECD interventions - responsive stimulation, enhanced nutrition and the combination of both - into an existing community-based health service. ${ }^{18}$ Without providing any robust criteria, the authors suggested that the most cost-effective one was the integrated intervention.

The current study seeks to fill the gap of a dearth of evidence on integration of ECD into the healthcare system. We aim to evaluate the operational feasibility, effectiveness and cost-effectiveness of an ECD intervention integrated into the healthcare system in 
Siaya County, Western Kenya. The specific objectives include to determine the effect of a health facility-based and health facility-based plus home-based ECD intervention on mother/caregiver ECD KAP; effect of the integrated intervention on growth and developmental outcomes of children aged 0-3 years; operational feasibility of the integrated intervention and, costeffectiveness of the integrated intervention from the provider's (health system)'s perspective. This study is expected to inform future implementation of ECD interventions integrated into the healthcare system in Kenya and other similar settings in SSA.

\section{METHODS}

\section{Study setting}

The study is being conducted in Siaya County in Western Kenya, where PATH has been supporting the Ministry of Health $(\mathrm{MOH})$ to integrate ECD into routine facility- and home-based health services in four sub-counties. Siaya County is among the 47 semi-autonomous county governments formed after the promulgation of the current Kenyan constitution. The county has six administrative sub-counties (Ugenya, Bondo, Gem, Rarieda, AlegoUsonga and Ugunja). ${ }^{19,20}$ Specifically, the study will be conducted in Bondo sub-county which has six wards. The projected total population for 2018 was 180,487, of whom $51.5 \%$ are female. The proportion of stunted children in the sub-county is high, at $56 \%$. There are seven inpatient health facilities in Bondo sub-county, including one referral hospital, as well as 45 outpatient health facilities. ${ }^{21}$

\section{Intervention}

PATH is currently implementing a model where ECD services targeting the youngest children and their caregivers (mainly biological mothers) are integrated into the routine health services in Siaya County in Kenya. Broadly, PATH's integrated ECD model has three components i.e. integration of ECD screening and counseling for developmental milestones and light-touch nutrition counseling in routine health facility clinical services (e.g., maternity, postnatal care, and growth monitoring and immunization) by health service providers such as nurses and clinical officers; playbox sessions in health facility waiting areas led by CHVs in order to make these spaces more child-friendly and integrate ECD counseling into lengthy wait times and, integration of ECD counseling into CHV home visits.

Components 1 and 2 are collectively referred to as the health facility-based ECD intervention and component 3 the home-based ECD intervention.

In integrating ECD into health services, PATH in collaboration with UNICEF and the WHO has adapted and expanded the module on CCD which was originally developed as part of the Integrated Management of
Childhood Illness. ${ }^{22}$ PATH's CCD adaptation provides more comprehensive and effective ECD counselling and screening tailored to specific health system touch-points, and also has a strong emphasis on promotion of optimal nutrition practices. The specific aim of CCD is to improve mother/caregiver awareness, sensitivity and responsiveness to a young child's learning and emotional needs, which in turn will result in improved childcare practices and consequently child developmental outcomes. PATH's approach focuses on the ongoing capacity building of service providers and their supervisors, and strengthening the enabling environment.

The PATH team will train and mentor facility-based health service providers (primarily nurses and clinical officers) and CHVs on play and communication. This forms the basis of the intervention package. In the health facility-based ECD intervention, health service providers will integrate ECD counseling and screening along with light-touch nutrition counseling into the following touch points that form part of the National Immunization Schedule in Kenya: immunizations given at birth or shortly after birth or the first postnatal care visit; immunization visits at six, 10 and 14 weeks and nine months; and, the six-month vitamin A supplementation visit. After delivery, mothers will receive the health facility-based ECD intervention through the six immunization touch points over a span of nine months. During the health facility visits, mother/caregiver-child dyads will also be exposed to playboxes. In the playbox sessions, CHVs and health service providers specifically teach caregivers how to engage in play with their children through responsive caregiving techniques and use of homemade toys.

In the home-based ECD intervention, as soon as possible after recruitment, mother/caregiver-child dyads will receive home-based ECD counseling by $\mathrm{CHVs}$ trained to integrate this content into their routine monthly $\mathrm{MOH}-$ mandated home visits. These visits will be supervised by community health extension workers (CHEWs), as well as members of the PATH team.

Intervention/study monitors recruited from lay health facility staff (e.g. clerks who books clients during routine service delivery) where possible will encourage each recruited mother/caregiver to attend all the six facilitybased immunization touch points as scheduled. They will also enhance the fidelity of the intervention by ensuring that all mother/caregiver-child dyads receive the ECD intervention during the immunization visits. The study monitors will track the participating caregivers through mobile phone (voice call or short message) reminders and home visits in case of a missed health facility visit.

Once the mother/caregiver-child dyads have received the facility-based ECD intervention, they will be encouraged to return to the health facility for follow-up visits (for data collection) once every nine months over the course of the remaining study period. These follow-up visits to 
the health facility will be aligned with routine $\mathrm{MOH}$ recommended growth monitoring visits. Children in all arms will receive routine $\mathrm{MOH}-$ mandated health services during health visits (e.g. weighing, height/length measurement, immunizations and sick childcare).

\section{Trial design}

The trial will use a mixed methods approach including records review, checklists, and direct measurements. We will conduct a three-armed, cluster-randomized controlled trial over a period of three years.

In arm 1, mother/caregiver-child dyads will receive the health facility-based ECD intervention that will be integrated into the routine facility-based $\mathrm{MOH}$ service touch-points. In addition, they will receive home visits from $\mathrm{CHVs}$ per the $\mathrm{MOH}$-mandated schedule, but these home visits will not integrate any ECD content.

In arm 2, mother/caregiver-child dyads will receive the health facility-based ECD intervention combined with the home-based ECD intervention that will be integrated into routine $\mathrm{CHV}$ home visits.

Arm 3 (control) will receive the current MOH's standard care only, which includes routine immunization and supplementation services mentioned previously and CHV home visits that do not integrate ECD content.

\section{Study hypotheses}

Relative to non-participants, we hypothesize that; mothers/caregivers in the health facility-based and health facility-based plus home-based ECD interventions will have improved ECD KAP; a higher proportion of children aged 0-3 years in the health facility-based and health facility-based plus home-based ECD interventions will achieve their developmental milestones; the health facility-based and health facility-based plus home-based ECD interventions are operationally feasible; the health facility-based and home-based ECD interventions are cost-effective and there is an incremental advantage of the health facility-based plus home-based ECD intervention over the health facility-based only intervention in terms of effect on caregiving practices and growth and developmental outcomes for children aged 0 3 years.

\section{Participant recruitment}

Participants will be recruited when they come for antenatal clinic (ANC) services during the third trimester of their pregnancy and subsequently followed up for the duration of the study (Table 1). After recruitment, pregnant women will be sensitized to the intervention during the ANC visit and will be encouraged to deliver at the same facility and to continue participating in the study. We anticipate that recruitment and baseline data collection will take two to three months.
The training and mentoring of healthcare providers who will deliver the health facility-based ECD intervention will happen just before study commencement to ensure that the health workers are ready to counsel new mothers on child stimulation by the time they deliver. Additionally, the CHVs facilitating the playbox sessions and those conducting home-based ECD counseling will be trained just before the study begins to ensure that they are ready to start providing the services before the child's first month of life. After the training, the PATH team, together with members of the sub-county Health Management Team (SCHMT) will provide supportive supervision and mentoring on a quarterly basis to ensure that the health workers are implementing the intervention according to the laid-down protocol.

\section{Sampling and sample size determination}

Within the study sub-county (Bondo), health facilities will be randomly selected from each of the six wards, and stratified at the ward level to reduce potential contamination between intervention and control participants. Facilities fulfilling the selection criteria, that is, having at least two clinical service providers (e.g. one nurse and one clinical officer) and maternal and child health $(\mathrm{MCH})$ and maternity sections, will be listed as eligible for selection. The health facilities will then be randomly selected from this list based on information on average client volume, annual deliveries, and health facility level. It is from these health facilities that we will recruit the mother/caregiver-child dyads to participate in the study. The selected health facilities will then be randomly allocated to the three arms by a statistician who is not part of the study personnel to ensure objectivity in allocation. To avoid contamination in this selection process, a buffer zone based on distance from one facility to another will be used to minimize interaction among caregivers visiting the different health facilities. We will work with public health facilities of any level that fulfil the stated criteria; however, the Bondo Referral Hospital which receives patients from the entire sub-county will be excluded in order to minimize potential contamination.

The sample size calculation is done by considering pairwise comparisons based on the assumption of $20 \%$ loss to follow-up and $80 \%$ power of detecting an effect size of 0.4 on caregiver practices, either in Arm 1 or Arm 2 (intervention arms) compared with Arm 3 (control). The estimated attrition rate is based on a study on improving infant feeding practices which found an average dropout rate of $8 \%$ over a nine-month follow-up period. ${ }^{23}$ There are two approaches of calculating the sample size when the data are clusters either at the community or health facility levels - in the current study, the cluster is a health facility. The first approach is to pre-determine the cluster size per arm, then estimate sample size per cluster and the required number of clusters to achieve the detectable difference. The disadvantage with this approach is that the number of clusters could be so large to the extent that it is not achievable in a study area. The second approach which is the one we have used, fixes a priori the cluster size per arm, and calculates the sample size per arm. We 
follow the procedures of Hemming and colleagues' study to estimate the sample size. ${ }^{24}$ In the current study, we assume that the ECD program could yield a standardized effect size of 0.4 in terms of ECD practices with an intracluster correlation (ICC) of $\rho=0.03 .{ }^{25}$ We also conjecture a confidence interval of $95 \%$, and a margin-oferror of $5 \%$.

We will generate three groups of mother/caregiver-child dyads and recruit 233 caregivers for each arm (Arm 1, Arm 2 and Arm 3). The clusters will be randomised using a pair-matching design. Each arm of the study will have six equally-sized clusters. The estimated cluster size is 39 (233/6). The total sample size is 699 mother/caregiverchild dyads. We will use consecutive recruitment until the desired sample size is attained. The study team decided on a cluster size of six per arm with 233 caregivers within each arm because recruiting this sample size is achievable within the study budget and is feasible within the study timelines.

\section{Participants' timeline}

Information on the time schedule of enrolment, interventions, assessments, and visits for participants is provided in Table 1. The main outcome of interest is caregiver KAP, while the secondary outcome is children's developmental status. During recruitment, caregivers will be asked about their sociodemographic characteristics and ECD knowledge and attitudes using a structured questionnaire. At time point one (T1) when children are aged between one and two months, caregivers will be interviewed about their ECD KAP, as well as children's developmental status using the ages and stages questionnaire - third edition (ASQ-3). Followup interviews and assessments with caregivers and their children will be conducted at nine months (T2 - month 910), 18 months (T3 - month 17-18) and 27 months (T4 month 25-28).

\section{Inclusion criteria}

Pregnant women 15+ years (who are considered emancipated minors in Kenya and therefore able to provide consent) in their third trimester, using the ANC services in the selected facilities, and who provide consent to participate in the study will be recruited. All the children will be recruited shortly after birth, including those with any form of disability as the intervention also targets such children.

\section{Exclusion criteria}

Pregnant women who are short-term residents (visiting the area and unlikely to remain in the study area for at least one year after recruitment) will be excluded from the study as they are unlikely to get adequate exposure to the intervention and provide adequate time for the evaluation. Also excluded will be women incapable of giving consent or participate in the study effectively (e.g. those with mental illness).

Table 1: Illustration of study design for health facility-based ECD intervention, health facility-based intervention combined with home-based ECD counselling and the standard care.

\begin{tabular}{|c|c|c|c|c|c|c|}
\hline \multirow[b]{3}{*}{ Time point } & \multicolumn{6}{|l|}{ Study period } \\
\hline & \multirow{2}{*}{$\begin{array}{l}\text { Enrolment } \\
\text { T0 pre-birth } \\
\text { (last trimester } \\
\text { of pregnancy) }\end{array}$} & \multicolumn{2}{|c|}{ Intervention period } & \multicolumn{2}{|c|}{ Post-intervention } & \multirow[t]{2}{*}{ Closeout } \\
\hline & & $\begin{array}{l}\text { T1 (month } \\
1-2 \text { of } \\
\text { child age) }\end{array}$ & $\begin{array}{l}\text { T2 (month } \\
9-10 \text { of } \\
\text { child age) }\end{array}$ & $\begin{array}{l}\text { T3 (month } \\
17-18 \text { of } \\
\text { child age) }\end{array}$ & $\begin{array}{l}\text { T4 (month } \\
25-28 \text { of } \\
\text { child age) }\end{array}$ & \\
\hline Enrolment & $\mathrm{x}$ & - & - & - & - & - \\
\hline Eligibility screen & $\mathrm{x}$ & - & - & - & - & - \\
\hline Informed consent & $\mathrm{x}$ & - & - & - & - & - \\
\hline Allocation & $\mathrm{x}$ & - & - & - & - & - \\
\hline \multicolumn{7}{|l|}{ Interventions } \\
\hline Group $1^{\mathrm{a}}$ & - & $\mathrm{x}$ & $\mathrm{x}$ & - & - & - \\
\hline Group $2^{b}$ & - & $\mathrm{x}$ & $\mathrm{x}$ & - & - & - \\
\hline Group $3^{c}$ & - & $\mathrm{x}$ & $\mathrm{x}$ & - & - & - \\
\hline $\begin{array}{l}\text { Routine MOH-mandated } \\
\text { facility-based services }\end{array}$ & $\mathrm{x}$ & $\mathrm{x}$ & $\mathrm{x}$ & $\mathrm{x}$ & $\mathrm{x}$ & - \\
\hline \multicolumn{7}{|l|}{ Assessments } \\
\hline Sociodemographic data & $\mathrm{x}$ & - & - & - & - & - \\
\hline $\begin{array}{l}\text { Caregiver knowledge and } \\
\text { attitudes }\end{array}$ & $\mathrm{X}$ & - & - & - & - & - \\
\hline Caregiver practices & - & $\mathrm{x}$ & $\mathrm{x}$ & $\mathrm{x}$ & $\mathrm{x}$ & - \\
\hline Child growth & - & $\mathrm{x}$ & $\mathrm{x}$ & $\mathrm{x}$ & $\mathrm{x}$ & - \\
\hline Developmental assessments & - & $\mathrm{x}$ & $\mathrm{x}$ & $\mathrm{x}$ & $\mathrm{x}$ & - \\
\hline Operational feasibility & $\mathrm{x}$ & - & $\mathrm{x}$ & $\mathrm{x}$ & - & - \\
\hline $\begin{array}{l}\text { Perception on effects of } \\
\text { intervention }\end{array}$ & - & - & - & - & $\mathrm{x}$ & - \\
\hline
\end{tabular}

${ }^{\mathrm{a}}$ Health facility-based ECD counselling; ${ }^{\mathrm{b} H e a l t h}$ facility + home-based intervention; ${ }^{\mathrm{c} C o n t r o l}$ (standard of care) 


\section{Data collection procedures}

\section{Quantitative data collection}

All quantitative data will be collected during the health facility visits over the implementation period. We will collect information on caregivers' ECD KAP and perceptions of the intervention. Caregiver KAP will be measured at each assessment point (Table 1) using questions on appropriate feeding practices and play and learning stimulation activities likely to promote holistic development in children. These items emanate from a measure of child stimulation within the home environment that has been culturally adapted and validated (modest internal consistency, with an alpha of 0.63 ) for use among infants in rural Kenya, and from tools used in earlier studies in Jamaica and Pakistan. ${ }^{10,26,27}$ The questions on caregivers' attitudes towards child stimulation are borrowed from the McGill parental attitude towards childrearing questionnaire. ${ }^{28}$

Caregiving practices will be assessed by maternal selfreport of responsiveness and the availability of opportunities for age-appropriate play and learning, involvement with the child, acceptance and provision of learning materials. The questions on caregiver practices are adapted from UNICEF's study in the Solomon Islands. ${ }^{29}$ Each item will be scored separately, and a point given for every positive response. A summated score will be derived. We will ask follow-up questions per practice to validate the mothers/caregivers' self-reports. Further, data from the maternal reports on caregivers' practices will be supplemented with video recordings of a randomly sampled $25 \%$ of the caregivers which will be coded using a checklist outlining specific activities that caregivers would routinely engage in with their children. Before recruitment, we will pre-test the tools with nonstudy mothers/caregivers to establish their comprehension of the items and appropriateness of the interview length. We will also request their suggestions on rephrasing.

At T0, we will capture information on mothers/caregivers' sociodemographic characteristics such as maternal age, education and occupation, crowding (persons per room) and household possessions. We will obtain additional information on the child's date of birth and birth weight from the MOH Mother-Child Booklet and other health records at T1. Where these documents are not available, we will rely on maternal recall. Health service providers will be sensitized on the importance of recording these data comprehensively. Data collectors will collect length, weight and head circumference data according to the standard protocol, at the data collection time points outlined in Table 1 (T1, T2, T3, T4). All interviews with mothers/caregivers will be conducted in the language with which they are most comfortable-Dholuo (the local language), Kiswahili (the national language), or English.
Direct assessment of children's growth and developmental status will be administered by the study team from two months onwards and will continue through the follow-up period (Table 1). We will administer the ASQ-3 through a combination of caregiver self-reported questions and direct observations, similarly to the procedures used in a study in South Africa and Zambia. ${ }^{30}$ The ASQ-3 is a globally used parent/caregiverreported, easy-to-use, reliable and validated screening instrument to identify potential developmental delays among children aged two to 60 months. ${ }^{31}$ The ASQ-3 taps into five developmental domains: communication, gross motor, fine motor, problem-solving and personalsocial development. The psychometric properties of the adapted version of the ASQ-3 used in South Africa and Zambia were consistent with other studies. Apart from the self-reports, caregivers will be requested to try each activity with their child to facilitate accurate item assessment. Items will be scored 'yes' (=10 points) if the child is able to perform the activity, 'sometimes' (=5 points) if the child tries and fails but the caregiver reports that the child could perform the activity sometimes, and 'no' ( $=0$ points) if the child is unable to perform the activity. The responses to each of the six questions in each domain will be summed to provide a domain score (0-60). Higher scores indicate more positive outcomes. A language adaptation protocol will be followed to ensure retention of the conceptual integrity of the original items in the translation. Field interviewers will be trained on how to conduct interviews with mothers/caregivers.

\section{Qualitative data collection}

Qualitative data will be collected prior to rolling out the integrated ECD intervention, then at 12 months, and subsequently each year during the follow up period. We will conduct key informant interviews (KIIs) with policy makers/implementers, healthcare managers and providers, CHVs and program staff at the national, county and sub-county levels as appropriate to determine their perceptions on the importance of the intervention, its feasibility, costs, and efficiency, among other aspects. We will also conduct in-depth interviews (IDIs) with caregivers to obtain an in-depth understanding of their KAP regarding childcare (all study arms), and their own personal experiences with the intervention (intervention arm only). Focus group discussions (FGDs) will be conducted with CHVs and male/secondary caregivers. The IDIs and FGDs will provide an overview of ECD practices at community level. Among the participants in the intervention group, we will seek information regarding their own experiences with the intervention delivery, and their perceptions on the intervention effects on parenting practices. Interviews with the control group participants will allow us to understand any difference in their knowledge and practices compared to those in the intervention group.

The total number of KIIs, IDIs and FGDs conducted will be determined by the data saturation point. However, we anticipate that approximately six KIIs, 18 IDIs, and six 
FGDs, three with CHVs and three with male/secondary caregivers, will be adequate. Each interview will be conducted by a moderator who will facilitate the session accompanied by a note taker who will take notes of the discussion and operate the audio recorder. All interviews will be conducted in the most preferred language of the respondents.

Data on operational feasibility (that is, how well the intervention works within the health system, and perceptions of service providers, health managers/supervisors and caregivers on acceptability and usefulness) will be collected at the time points of qualitative data collection at the beginning of the study March, 2018; mid-study point - August 2019; and at the end of the study - February 2021. The proposal is to assess key feasibility and operational issues associated with the facility-based ECD intervention and the combined intervention in a Kenyan setting. The main criteria to determine the questions used to address operational feasibility and the data collection methods are summarized in Table 2.

As part of establishing operational feasibility, we will also monitor implementation fidelity to determine whether or not the intervention components are being implemented as planned. We will also conduct exit interviews on $10 \%$ of the caregivers to confirm if they are actually receiving the intervention. A field supervisor/monitor will facilitate monitoring of the intervention through regular checks of the health facility records to capture information on dates of caregiver visits and exposure. Furthermore, we will analyze PATH's routine monitoring data to understand if the ECD intervention is being delivered with the desired level of quality once service providers have been trained to provide these services. In the PATH mentoring model, PATH staff and/or government mentors use a checklist to score trained service providers by observing the quality of ECD service delivery (both technical knowledge and interpersonal skills) and "graduate" them once they reach a desired level of quality of service delivery.

\section{Costing data collection}

We will estimate the costs of integrating the ECD intervention in facility-based health services and home visits, and will also conduct a cost-effectiveness analysis to examine the value for money of the ECD intervention in influencing caregiver ECD KAP and child growth and developmental outcomes. The costing will be carried out from the health system's perspective and will focus on the costs incurred by the government and implementers in the delivery of the ECD intervention. Items such as caregivers' travel costs, lost labor time and other societal/opportunity costs will not be taken into account.

The costing study will assess: the annual costs per health facility and per child-caregiver dyad. This will include costs for mentoring, placement and replenishment of playboxes, $\mathrm{CHV}$ home visits, printing of ECD materials, and time needed for service delivery; and, the introduction costs of the health facility-based and homebased ECD interventions. The introduction costs will include initial training costs, cost associated with mentoring service providers until they deliver ECD services with the desired level of quality, costs for sensitization and awareness-raising activities and the supervision/monitoring costs. The introduction costs will be annualized.

We will use both primary and secondary data. Primary data will be obtained through a self-reported estimate on the time healthcare service providers take to deliver the health facility-based ECD intervention (time use data). Further, we will obtain information from $\mathrm{CHVs}$ on time spent on the home visits. Secondary data will be collected by capturing the costs associated with rolling out the intervention from the healthcare system's perspective. The latter costs include PATH staff salaries, transport to the health facilities and training venues, per diems, etc., and will be determined by analyzing PATH's financial documents.

\section{Outcomes}

The primary outcome is caregivers' KAP regarding ECD (stimulation and responsive caregiving). The secondary outcomes are child growth and developmental outcomes, operational feasibility and cost and cost-effectiveness of the health facility-based and health facility-based plus home-based ECD interventions.

\section{Data management and analysis}

\section{Data quality}

Data collection will be done electronically by trained field interviewers using tablets/phones, and will be supervised by trained team leaders and the research team. During fieldwork, data quality of quantitative data will be enhanced through regular spot checks and sit-ins of approximately $5-10 \%$ of each field interviewer's daily work to verify data authenticity. The field supervisor will cross-check the quality of the data before they are transferred to the database. All inconsistencies will be resolved prior to data analysis. An automated routine check on completeness, correctness and consistency will also be run on $100 \%$ of the data. A discrepancy report will then be generated to help in following up on any inconsistencies/errors with the responsible interviewer.

The quality of qualitative data will be enhanced through recruitment and training of qualified and experienced field interviewers. Furthermore, data collection will mainly be done by the research team, with the trained interviewers assisting in note-taking. Pretesting of the tools and debriefing after pretesting will be done to enhance data quality. The interviews will be transcribed verbatim by an experienced transcriptionist and double coding of about $10 \%$ of the transcripts will also be done to ensure consistency in the application of the codes. 
Table 2: Summary of $\mathbf{1 0}$ criteria and data collection methods for operational feasibility assessment.

\begin{tabular}{|c|c|c|}
\hline \multirow{2}{*}{\multicolumn{2}{|c|}{$\begin{array}{l}\text { Main criteria } \\
\text { How well will the ECD intervention work in the health system? }\end{array}$}} & \multirow{2}{*}{ Data collection methods } \\
\hline & & \\
\hline Performance & $\begin{array}{l}\text { Does the intervention address any unmet needs of providers and } \\
\text { beneficiaries/community? How does it affect the system? }\end{array}$ & \multirow{6}{*}{$\begin{array}{l}\text { Review of program } \\
\text { documents; interviews } \\
\text { and/or focus group } \\
\text { discussions (FGDs) with } \\
\text { mothers/caregivers; } \\
\text { interviews with program } \\
\text { staff; interviews and/or } \\
\text { healthcare managers and } \\
\text { providers; and, interviews } \\
\text { with key policy } \\
\text { makers/implementers both at } \\
\text { county and national level. }\end{array}$} \\
\hline Information & $\begin{array}{l}\text { Does the intervention provide caregivers, health service providers, and } \\
\text { managers with useful information? }\end{array}$ & \\
\hline Costs & $\begin{array}{l}\text { What are the costs to integrate ECD intervention into the healthcare } \\
\text { system? }\end{array}$ & \\
\hline Control & $\begin{array}{l}\text { Does the ECD intervention have adequate controls to protect resources } \\
\text { and guarantee accuracy of data and information? }\end{array}$ & \\
\hline Efficiency & Does the ECD intervention make good use of available resources? & \\
\hline Service & $\begin{array}{l}\text { Does the ECD intervention provide desirable and reliable service for } \\
\text { those who need it? Is the intervention scalable? }\end{array}$ & \\
\hline \multicolumn{3}{|c|}{ Is the integration of ECD into the health system perceived to be acceptable and useful } \\
\hline \multirow[t]{2}{*}{ Support } & $\begin{array}{l}\text { Does the health facility, sub-county and county management and } \\
\text { community health strategy support the ECD intervention? }\end{array}$ & \multirow{4}{*}{$\begin{array}{l}\text { Interviews with health } \\
\text { facility management and } \\
\text { county health management } \\
\text { team; interviews and/or } \\
\text { FGDs with } \\
\text { mothers/caregivers; } \\
\text { interviews and/or FGDs with } \\
\text { healthcare providers and } \\
\text { CHVs. }\end{array}$} \\
\hline & Is the ECD intervention acceptable or useful for mothers/ caregivers? & \\
\hline Resistance & $\begin{array}{l}\text { What are resistance points to the intervention, if any, from the point of } \\
\text { view of management, provider, and caregivers? How can that } \\
\text { resistance be overcome? }\end{array}$ & \\
\hline Adaptable & $\begin{array}{l}\text { Will mothers/caregivers and healthcare providers adapt to the } \\
\text { introduction of the intervention? } \\
\text { What else is needed to aid the adaptation of the introduction of the } \\
\text { ECD intervention? }\end{array}$ & \\
\hline
\end{tabular}

\section{Quantitative data analysis}

After the data are cleaned, quantitative data will be analyzed using Stata (StataCorp, College Station, TX, USA). The first set of analyses will consist of descriptive statistics of participants' characteristics at baseline. In addition, we will compare some baseline measurements between the control group and intervention group using the t-test adjusted for clustering at the health facility level for continuous variables, and cluster-adjusted chi-square for binary variables.

The second set of analysis will consist of assessing the causal effect of the ECD intervention via the differencein-differences (DID) estimator, multilevel DID and mixed linear model. The DID is used to estimate the average difference between outcome values for the two groups (intervention and control groups) at baseline and the follow-up periods. The DID estimator will be applied at different time points. ${ }^{1}$ With this fixed-effect estimator, we could add other covariates. However, since we have few health facilities, we will report the findings using the wild cluster bootstrapped standard error. ${ }^{32}$ We will carry out other robustness checks of the magnitude of the treatment effect using other estimating tools such as the multilevel DID and mixed linear models. These estimators account for the clustering of the outcome at the health facility level. Given the longitudinal nature of the survey, we will also investigate the possible linear change in the outcomes according to the length of the implementation period.
Individual items on the ASQ-3 will be reviewed for missing data, and floor and ceiling effects. In the case where more than $10 \%$ of the responses are missing, the data will be excluded from further analysis. We will also sum the item scores to establish children's performance levels at baseline and endline in order to identify domains with acceptable variability.

\section{Qualitative data analysis}

Qualitative data will be transcribed and translated before being transferred to NVivo (QSR International Pty Ltd., Burlington, MA, USA) to identify primary and meta codes and major themes. Analysis across all transcripts will be done thematically. ${ }^{33}$ The imported data will be coded and sorted based on the key operational feasibility questions. Sorted data will then be summarized thematically in line with the operational feasibility questions. Based on the analysis outputs, the operational feasibility of the proposed ECD intervention will be rated on a scale of 1 (very low) to 5 (very high) for each of the 10 criteria.

\section{Costing data analysis}

The costing data per health facility, and per mother/caregiver-child dyad and the effectiveness data will be used as inputs to calculate the cost-effectiveness of ECD integration. Costing data will be summarized and described for each cost item and sensitivity analysis will 
be carried out to estimate the cost of the ECD intervention. We will determine the incremental cost of implementing the ECD interventions. Hence, at different time points, we will estimate the cost per one-unit increase of mother/caregivers' knowledge on ECD, cost per one-unit improvement in mother/caregivers' attitudes on ECD, cost per one-unit improvement in mother/caregivers' practices, and cost per one-unit improvement in child growth and developmental outcomes.

Effectiveness will be measured through improvements in ECD KAP and developmental scores. A summated score will be calculated across all the developmental domains. We will calculate multiple cost-effectiveness ratios for the multiple effectiveness measures, that is, cost per unit increase in caregivers' ECD KAP and children's developmental scores. Furthermore, with a view to informing the input costs per child associated with different ECD implementation and scale-up models, we will estimate (hypothetical) input costs associated with multiple scenarios. These hypothetical costing scenarios are more likely to represent the "real" cost of scaling up the intervention, as the current standalone five-day ECD training and PATH-led supervision and mentoring model may not be conducive for scale-up and therefore not attractive to governments.

\section{Ethical considerations}

The study has been approved by the Amref Health Africa's Ethics and Scientific Review Committee (ESRC), a nationally recognized ethical review committee, approved by the Government of Kenya, reference number: P314/2017. The investigators will uphold the fundamental principles regarding research on human subjects: respect for persons, beneficence, nonmaleficence and justice. Informed consent will be obtained from all the eligible participants following full disclosure regarding the study before data collection. The information sheet will be read out in the local language for those who cannot read, and they will be asked to provide a thumbprint to signify their consent. Proxy consent for children will be obtained from their mothers/caregivers. All survey data will be collected privately and will be treated with utmost confidentiality. Study participants will be informed that their participation is voluntary. They will be assigned unique study identifiers to ensure anonymity of their information. The contact information of the principal investigator and the ESRC is provided on the information sheet for participants in case of any concerns regarding their participation.

\section{DISCUSSION}

The cluster-randomized controlled trial described in this protocol aims to evaluate the operational feasibility, effectiveness and cost-effectiveness of health facility- and home-based plus health facility-based ECD interventions in a rural setting in western Kenya. The primary objective is to determine the effect of the interventions on mother/caregivers ECD KAP. The interventions are based on an adaptation and expansion of the CCD by PATH. The CCD aims to improve mother/caregiver awareness, sensitivity and responsiveness to a young child's learning and emotional needs, which in turn will result in better childcare practices. When children are stimulated appropriately in their early years, they have a better likelihood to thrive throughout childhood and later in life, to attain better health, education and socioeconomic outcomes. On the other hand, lack of stimulation in the early years can impair young children's emotional, social, physical and cognitive development. Although counseling on ECD and screening for developmental delays are expected to be carried out during routine health service delivery in Kenya, they are generally not carried out in practice. In recognition of this gap, PATH seeks to integrate stimulation and responsive caregiving into health service provision through training and ongoing mentoring of facility-based health service providers and CHVs.

The types of programs that have been evaluated in earlier studies have been delivered through different platforms including center-based programs where children spend considerable amounts of time in ECD centers; ECD programs directed towards improving parenting and other caregiving; and, comprehensive ECD programs (those that included different aspects such as vaccination, breastfeeding and complementary feeding, growth monitoring and nutritional supplementation) that are integrated into existing community-based systems. ${ }^{15,35,36}$ The results from these evaluations suggest that there are considerable gains to be made from expanded ECD programs, particularly in low-income settings. Given the positive impact of ECD programs, there is need for more systematic evaluations of ECD programs, particularly those that have the potential for scale up and sustainability, such as those embedded within the health systems context. As has been highlighted in the literature, delivery of ECD interventions can easily be scaled up through existing health and nutrition services for mothers and infants. ${ }^{37}$

Past evaluations of integrated ECD programs also provide evidence on the feasibility of integrating ECD activities into the health system. A review of integrated ECD programs in Bangladesh indicates that such programs are beneficial for children in terms of improved outcomes, and have gained the support of relevant government ministries. ${ }^{38}$ One of the suggestions arising from this review, which has been considered in the design of the current study, is the need to simplify the process of integration through the use of brief ECD messages which can be easily merged with existing health programs. Other means of enhancing the acceptability of such programs is encouraging community awareness through community and household meetings and media 
campaigns, strengthening community clinics and the use of a community-based behavioral change approach.

In line with recommendations made from the findings of a recent review, one of the strengths of the current study is its potential to be effective due to the fact that the ECD program intends to reach children early, during the most vulnerable period from conception to two years; it is likely to address multiple risk factors such as poverty and the lack of stimulating environments for children; and has potential to be integrated across multiple disciplines. ${ }^{5}$ As the children grow older, attention will move towards early learning, and this provides an opportunity for coordination between the ministries of health and education. The integration of health and education delivery platforms will create possibilities for breaking down the 'silos' that exist among departments that may have different priorities and regulations. As has been highlighted earlier on, the use of a shared platform for delivery will maximize the impact of an integrated intervention and promote the achievement of health- and education-related sustainable development goals (SDGs), that is, SDGs 3 and $4 .{ }^{39}$ Additionally, in testing the costeffectiveness of the integrated program, the study will likely provide a strong case for subnational investment in such a program, especially if the government ministries see evidence of a substantial return.

One major limitation is the lack of explicit involvement of men in the ECD activities. Male members of families may not readily support ECD intervention activities, and yet, their participation is crucial to the success of implementation. As they are more likely to be the heads, males play a big role in the decisions made concerning what happens within their households, and their lack of involvement may limit the participation of female caregivers.

\section{CONCLUSION}

The findings of this study will expand the available evidence base on integrated ECD interventions, as most studies on ECD interventions for the youngest children have taken place in settings outside of sub-Saharan Africa and/or have been conducted in research settings (i.e., not within the context of a real-world health system). The data generated will provide much-needed information for program design and intervention replication - both in Kenya and in other sub-Saharan African countries. Furthermore, findings from this study will inform the Kenyan MOH's plans to scale up ECD service delivery within the health system. Results obtained through this study will be made available to participants in the study (caregivers, CHVs, health service providers) and key governmental and nongovernmental stakeholders in Siaya County and nationally, and internationally. Given the current strong political will and commitment towards improving outcomes for young children in line with the SDGs, there is the need for further research on the most important aspects to be considered to ensure quality is maintained when scaling up an integrated ECD intervention at the population level. Further, strategies to promote male involvement in ECD activities is another area for possible further investigation.

\section{ACKNOWLEDGEMENTS}

The study is funded by the ELMA Philanthropies, with an additional sub-grant from PATH through funding from the Conrad N. Hilton Foundation.

Funding: ELMA Philanthropies

Conflict of interest: None declared

Ethical approval: The study was approved by the Amref Health Africa's ESRC

\section{REFERENCES}

1. Dua T, Tomlinson M, Tablante E, Britto P, Yousfzai A, Daelmans B, et al. Global research priorities to accelerate early child development in the sustainable development era. The Lancet Global Health. 2016;4:e887-9.

2. Black MM, Walker SP, Fernald LCH, Andersen CT, DiGirolamo AM, Lu C, et al. Early childhood development coming of age: science through the life course. The Lancet. 2017;389(10064):77-90.

3. Global Research on Developmental Disabilities Collaborators. Developmental disabilities among children younger than 5 years in 195 countries and territories, 1990-2016: a systematic analysis for the Global Burden of Disease Study 2016. Lancet Global Health. 2018;6:e1100-21.

4. Walker SP, Powell CA, Grantham-McGregor SM, Himes JH, Chang SM. Nutritional supplementation, psychosocial stimulation, and growth of stunted children: The Jamaican study. Am J Clin Nutr. 1991;54(4):642-8.

5. Britto PR, Lye SJ, Proulx K, Yousafzai AK, Matthews SG, Vaivada T, et al. Nurturing care: promoting early childhood development. The Lancet. 2017; 389(10064):91-102.

6. Walker SP, Wachs TD, Gardner JM, Lozoff B, Wasserman GA, Pollitt E, et al. Child development: risk factors for adverse outcomes in developing countries. The Lancet. 2007;369(9556):145-57.

7. Engle PL, Menon P, Haddad L. Care and nutrition: concepts and measurement. World Development. 1999;27(8):1309-37.

8. Engle PL, Fernald LCH, Alderman H, Behrman J, O'Gara C, Yousafzai A, et al. Strategies for reducing inequalities and improving developmental outcomes for young children in low-income and middleincome countries. Lancet. 2011;378(9799):1339-53.

9. World Health Organization UNCsF, World Bank Group. Nurturing care for early childhood development: a framework for helping children survive and thrive to transform health and human potential. Geneva: World Health Organization; 2018 . 
10. Chang SM, Grantham-McGregor SM, Powell CA, Vera-Hernández M, Lopez-Boo F, BakerHenningham $\mathrm{H}$, et al. Integrating a Parenting Intervention With Routine Primary Health Care: A Cluster Randomized Trial. Pediatrics. 2015;136(2):272-80.

11. Slemming W, Saloojee H. Beyond survival: The role of health care in promoting ECD. 2013.

12. Ertem IO, Atay G, Bingoler BE, Dogan DG, Bayhan A, Sarica D. Promoting Child Development at SickChild Visits: A Controlled Trial. Pediatrics. 2006;118(1):e124-31.

13. Yousafzai AK, Rasheed MA, Rizvi A, Armstrong $\mathrm{R}$, Bhutta ZA. Effect of integrated responsive stimulation and nutrition interventions in the Lady Health Worker programme in Pakistan on child development, growth, and health. The Lancet. 2014;384(9950):1282-93.

14. Grantham-McGregor SM, Fernald LCH, Kagawa RMC, Walker SP. Effects of integrated child development and nutritioninterventions on child development and nutritional status. Ann New York Acad Sci. 2014;1308:11-32.

15. Powell C, Baker-Henningham H, Walker S, Gernay J, Grantham-McGregor S. Feasibility of integrating early stimulation into primary care for undernourished Jamaican children: cluster randomised controlled trial. BMJ. 2004;329.

16. Tomlinson M, Hartley M, le Roux I, RotheramBorus MJ. The Philani Mentor Mothers Intervention: Neighbourhood wide impact on child growth in Cape Town's peri-urban settlements. Vulnerable Child and Youth Studies. 2016;11(3):221-2.

17. Potterton J, Stewart A, Cooper P, Becker P. The effect of a basic home stimulation programme on thedevelopment of young children infected with HIV. Developmental Med Child Neurol. 2010;52(6):547-51.

18. Gowani S, Yousafzai AK, Armstrong R, Bhutta ZA. Cost effectiveness of responsive stimulation and nutrition interventions on early child development outcomes in Pakistan. Ann New York Acad Sci. 2014;1308:149-61.

19. Kenya National Bureau of Statistics. County Report: Siaya County. Nairobi, Kenya: Kenya National Bureau of Statistics; 2015.

20. Ministry of Health. County Intergrated Development Plan, 2013 to 2017: County of Siaya. 2013.

21. Kenya National Bureau of Statistics. Siaya County Multiple Indicator Cluster Survey 2011. Nairobi, Kenya: Kenya Naitonal Bureau of Statistics; 2013.

22. UNICEF. Care for Child Development Package. New York, NY: United Nations Children's Fund; 2015.

23. Mukuria AG, Martin SL, Egondi T, Bingham A, Thuita FM. Role of Social Support in Improving Infant Feeding Practices in Western Kenya: A
Quasi-Experimental Study. Global Health Sci Pract. 2016;4(1):55-72.

24. Hemming K, Girling AJ, Sitch AJ, Marsh J, Lilford RJ. Sample size calculations for cluster randomised controlled trials with a fixed number of clusters. BMC Med Res Methodol. 2011;11:102.

25. Walker PS, Powell C, Chang SM, Henningham HB, McGregor SG, Hernandez MV, et al. Delivering Parenting Interventions through Health Services in the Caribbean: Impact, Acceptability and Costs. 2015.

26. Holding P, Abubakar A, Obiero E, van de Vijver FJR, editors. Validation of the Infant-Toddler HOME Inventory among households in low income communities at the Kenyan Coast. 19th International Congress of the International Association for Cross-Cultural Psychology; 2011.

27. Rahman A, Iqbal Z, Roberts C, Husain N. Cluster randomized trial of a parent-based intervention to support early development of children in a lowincome country. Child: Care, Health and Development. 2008;35(1):56-62.

28. Cohen M. Parental attitudes toward child-rearing : toward the development of a new measure Canada: McGill University; 1990.

29. UNICEF. Study of Parental Knowledge, Attitudes and Practices Related to Early Childhood Development. Suva, Fiji: United Nations Children's Fund; 2014.

30. Hsiao C, Richter L, Makusha T, Matafwali B, van Heerden A, Mabaso M. Use of the ages and stages questionnaire adapted for South Africa and Zambia. Child Care Health Development. 2017;43(1):59-66.

31. Squires J, Bricker DD, Twombly E, Potter L. Ages \& Stages Questionnaires: A Parent-Completed Child-Monitoring System (Third Edition). Baltimore, MA: Paul Brookes Publishing Co; 2009.

32. Cameron AC, Gelbach JB, Miller DL. BootstrapBased Improvements for Inference with Clustered Errors. Review of Economics and Statistics. 2008;90(3):414-27.

33. Lacey A, Luff D. Trent Focus for Research and Development in Primary Health Care: Qualitative Data Analysis. Trent Focus; 2001.

34. Kagitcibasi C, Sunar D, Bekman S. Long-term effects of early intervention: Turkish low-income mothers and children. J Applied Developmental Psychol. 2001;22(4):333-61.

35. Armecin G, Behrman JR, Duazo P, Ghuman S, Gultiano S, King EM, et al. Early childhood development through an integrated program: evidence from the Philippines. Washington, DC: The World Bank; 2006. Contract No.: IE2.

36. Behrman JR, Cheng Y, Todd PE. Evaluating Preschool Programs When Length of Exposure to the Program Varies: A Nonparametric Approach. Rev Economics Statistics. 2004;86(1):108-32.

37. Richter LM, Daelmans B, Lombardi J, Heymann J, Boo FL, Behrman JR, et al. Investing in the foundation of sustainable development: pathways to 
scale up for early childhood development. The Lancet. 2017;389(10064):103-18.

38. Hamadani JD, Nahar B, Huda SN, Tofail F. Integrating early child development programs intohealth and nutrition services in Bangladesh: benefitsand challenges. Ann New York Acad Sci. 2014;1308:192-203.

39. Sharma R, Gaffey MF, Alderman H, Bassani DG, Bogard K, Darmstadt GL, et al. Prioritizing research for integrated implementation of early childhood development and maternal, newborn, child and adolescent health and nutrition platforms. J Global Health. 2017;7(1).

Cite this article as: Kitsao-Wekulo P, Donfouet HPP, Onyango S, Wanjohi M, Sen D, Frey M, et al.

Evaluation of the feasibility and effectiveness of a health facility-based combined with home-based early childhood development intervention in Siaya County, Kenya: a cluster-randomized control trial. Int J Clin Trials 2020;7(3):200-11. 